\title{
1 Sustainability science as a transformative social learning process
}

\author{
Ariane König
}

\section{Existential challenges of the twenty-first century}

Throughout history mankind has caused unintended changes in the natural environment, including phenomena such as extinction of vulnerable species and soil erosion from deforestation (Crosby, 2015). These changes, however, were confined to local or regional scales. Unprecedented in the twenty-first century is that science and technology associated with industrialization, whilst they have further transformed the conditions of life for humanity, now create environmental impacts at the global scale. Our socio-industrial-agricultural metabolism and land-cover changes are significantly altering the earth system's natural bio-geo-chemical cycles and threaten the integrity of the biosphere, which both when unperturbed contributed to maintain the relatively stable conditions under which humanity has thrived over the last 10,000 years.

The existential problems of the human civilization in the twenty-first century are complex as they relate to interactions between humans and their environment in a world that is experiencing accelerating changes in the technological, cultural, political, economic, and environmental spheres. Moreover, changes in all these spheres are globally interconnected and interdependent. Traditional disciplinary fields of 'normal' science and static approaches to management and governance relying on prediction, regulation, and control can play only a limited role in resolving such complex problems. Experts in different fields of knowledge in the natural and social sciences often fail to understand each other, and we are drowning in specialised expert reports that often do not sufficiently account for interdependencies and feedbacks between changes in these different spheres. New approaches to combining knowledge co-creation and distributed governance should be designed to enable the effects of human-environment interactions to be continuously and iteratively monitored, evaluated, judged, and acted upon, based on social norms that respond to locally determined sustainability issues.

This book's main premise is that one of the most fundamental challenges we face as we are affecting the functioning of the entire planetary system, is to develop new approaches to knowledge co-creation and governance that will enable us to relate to our environment and to each other in view of more complex interdependencies between local and global circumstances, in how we conceive of the natural and social worlds, now and in the future. The silo-based approach to science and expertise, government and practice, with strict separation of research in the natural sciences and social sciences and the humanities that has co-evolved with industrialization, is no longer adequate for our civilization to cope with twenty-first-century challenges. New approaches to combining research, governance, and learning in 
communities of public authorities, stakeholders, and scientists are required to complement our increasingly fragmented knowledge fields and to learn to change the unsustainable ways in which we relate to our environment and to each other. These new approaches should draw on new opportunities for new forms of knowledge co-creation and governance in a networked society; the hope is that such new forms of knowledge co-creation with broader public engagement might also contribute to address the current great risks of democratic disengagement and posttruth politics (as highlighted by Wals and Peters, Chapter 2 in this book). Not only may we have reached an end to a long period of stability in the biosphere of our planet, providing us with living conditions in which we humans thrived, but we may have also reached an end of a period of stability of the type of specialised expert knowledge that governments have drawn upon in modernity (or 'epistemic stability') (Maggs \& Robinson, 2016). In the words of Michael Hulme, 'where science is practiced, by whom and in what era, affects the knowledge that science can produce' (Hulme, 2009, as cited in Maggs \& Robinson, 2016).

In this book, we therefore introduce a new conception of science that emerges from dialogues on the need for a more future-oriented and systemic social learning process. The overarching goal of this 'transformative sustainability science' is for humanity to become better at embracing complex relationships and interactions (complexity) that depend on local settings and people (contingency); contradictions and conflicts between diverse worldviews; and associated sets of values, uncertainty, and ignorance when interacting with each other and with our planet's life support system which we are a part of. We need to become better at understanding the social and cultural dimensions of these challenges to knowledge creation (Maggs \& Robinson, 2016; Castree, 2015; O’Brien, 2015). A starting point is to develop a critical and reflective mind-set towards what we can and cannot know, how we know, and why we want to know in an age of accelerating and interconnected change. Furthermore, we need to practice to understand different facets of complex situations through very different perspectives rather than just defending a viewpoint through a particular (organizational) lens associated with a particular set of interests (see also Chapter 2). Similar questions can be asked about learning with a focus on how we might better link learning in individuals, organizations, and societies. In these processes, scientific analysis serves as a basis not for predication and control, but for social learning (e.g. Ison et al., 2007). Accordingly, such approaches should enable reflection, review, and transformation of the prevailing social structures and practices, technologies, research, and learning approaches in the light of new learning Digital technologies for networked societies have a role to play.

This implies fundamental changes in - or transformation of - currently prevailing mechanisms for social coordination, including organisation of the economy and governance in our society. At present this is largely accomplished through hierarchical government and through market rules that assume competing utility-maximising rational actors (e.g. Ostrom, 2010). Figure 1.1 provides an overview on transformations in prevailing patterns for social organisation, economy and communications over the course of human evolution. The emergence of the networked knowledge society in the twenty-first century presents huge opportunities and novel types of virtual spaces that can be leveraged in such a transition and is already significantly altering social coordination, including ways in which knowledge is co-created.

The remainder of this chapter introduces the practice of sustainability science as one promising new approach to organizing knowledge co-creation across silos of expertise and practice. First, we introduce sustainability science and different 

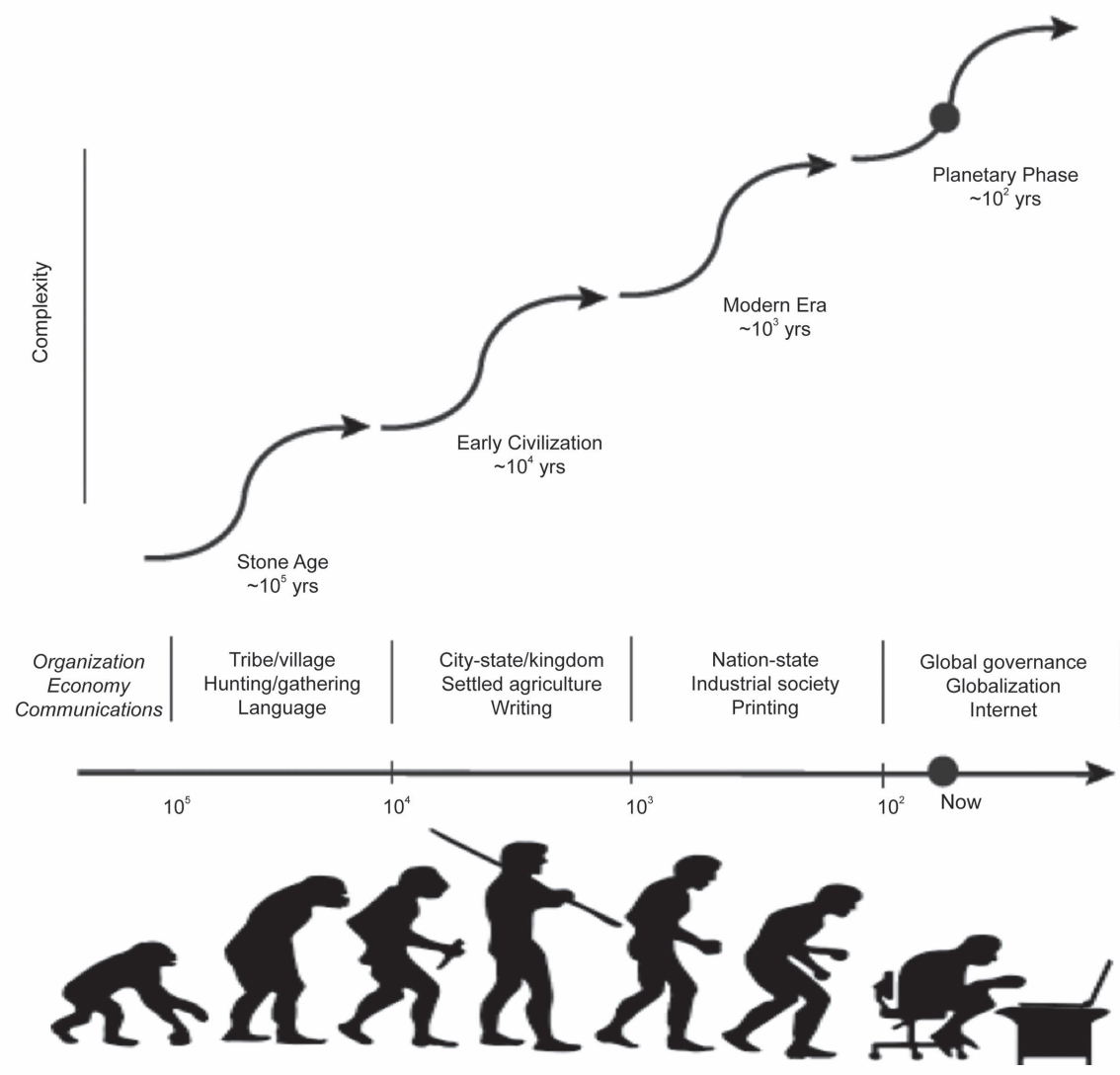

Figure 1.1 Phases from human history

Source: Adapted from Paul Raskin, 2016

meanings attributed to it in the academic literature. Second, we discuss why this approach to science may be considered problematic. Third, we explore a diversity of purposes and approaches that can be associated with sustainability science. Fourth, we focus on transformative sustainability science as one approach that is akin to a transformative social learning process and ask what exactly we envisage shall be transformed. The second part of this chapter presents the structure of the entire book and summarises the individual chapters.

\section{What is sustainability science and what makes it transformative?}

Sustainability science is an emerging approach to science that actively seeks improved ways for governing human-environment interactions. One main goal is to leverage social and natural science and technology for a transition towards sustainability (Jerneck et al., 2011). Some engaged scientists consider sustainability a field of knowledge that relies on integrating across diverse established fields of knowledge (Kates et al., 2001; Clark \& Dickson, 2003; Clark, 2007). One of the first publications 


\section{Ariane König}

referring to 'sustainability science' describes it as an interdisciplinary field of research that takes a systems approach to understand dynamic interactions between nature and society (Kates et al., 2001; Clark \& Dickson, 2003; Matson et al., 2016). Core research questions include: 'How can today's relatively independent activities of research, planning, observation, assessment and decision-support be better integrated into systems for adaptive management and social learning?' (Kates et al., 2001).

Some leading scholars distinguish between descriptive and transformative sustainability science (Wiek et al., 2011; Miller et al., 2013; Wiek \& Lang, 2015). On the one hand, descriptive sustainability science that is largely practiced by scholars in the environmental and earth sciences states as a main objective the building of a body of knowledge on the functioning of the earth system to inform the traditional top-down policy-making processes. For example, a group of very successful researchers set out to determine planetary boundaries for creating a safe operating space for humanity that is to inform evidence-based policy making (Rockström et al., 2009; Steffen et al., 2015). On the other hand, in transformative (or sometimes also called 'transformational') sustainability science, in line with pragmatic views on knowledge and science, the stated goal is to fundamentally change human-environment interactions and all associated social practices and expectations in a process that will necessarily question prevailing values, worldviews, and ways of knowing and doing. Such research at its best achieves the combination of approaches that are critical and challenge driven. (This book refers to 'challenge driven' rather than 'solution oriented', as we consider sustainability challenges in highly dynamic worlds not as 'solvable', but as amenable to being addressed in an iterative learning process over time.) Sustainability in this case can be considered an emergent phenomenon, consisting of sets of new expectations and social practices from a societal conversation that is scientifically informed (Robinson et al., 2013).

Together with a range of other scholars in this book we thus take a procedural view and consider transformative sustainability science as a social deliberative process, a different approach to conducting science that engages experts and stakeholders with diverse perspectives on complex challenges (Miller et al., 2013; Wiek \& Lang, 2015; Robinson et al., 2011; Schneidewind \& Singer-Brodowski, 2014; Schneidewind et al., 2016; Grunwald, 2016; König, 2015). Similar to related calls for a new social contract for global change research within the field of geography (Castree, 2015), an approach to research is sought that takes the human dimension seriously. One requisite to this research is to clearly acknowledge the political dimension in the conduct of science - for example, by problematizing human agency in pluralist societies, in which diverse groups defend different sets of values. A monolithic view of the role of science as preaching simple truths to power is seen as inadequate by many scholars concerned with developing science for sustainability (O'Brien, 2015). We also require innovation in the ways that science can foster changes in social practice in as many diverse groups as possible, not merely by serving as expert-shaped evidence for policy makers.

Transformative sustainability science starts from the assumption that in order to change social practice affecting how we understand and relate to our environment and draw on environmental and social resources, research needs to be co-created in a collaborative process that connects diverse disciplinary perspectives with practice. Figure 1.2 describes a process for co-creation of four knowledge types that relies on rigorous participatory scientific inquiry and quality control. In the boxes shaded in grey relying on dialogue between diverse participants, science is on tap, not on top. Different methods can be used in different stages to ensure that a future oriented 


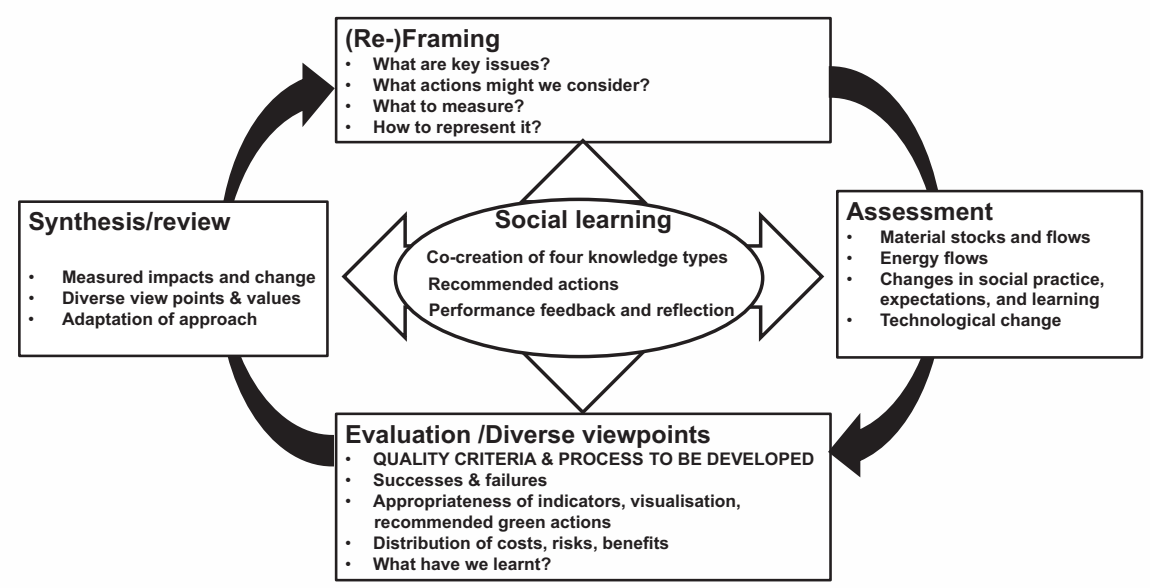

Figure 1.2 Transformative sustainability science: an iterative process with four stages (Re-) Framing: A dialogue for participatory consideration of the following questions: What are key issues? What actions might we consider? What should be measured? How shall we represent our findings? Assessment: Serves to characterize changes in the core variables over time and space in terms of material and energy stocks and flows; technology, its uses and users; and social practice, expectations, and learning and how these may be interrelated. Evaluation: A dialogue for participatory development of criteria and a process to determine diverse perspectives on successes and failures; distribution of costs, risks, and benefits; appropriateness of indicators; visualisation/representations; and recommended actions addressing the question 'What have we learnt'? This takes a humble attitude by all engaged about what and how we know and requires empathy (based on Jasanoff, 2003). Synthesis/review: Measured impacts and change are reviewed, as are diverse viewpoints and values, as well as joint judgments, leading to reframing the adaptation of our approach.

systems view that is sensitive to diverse perspectives is adopted. These can include collaborative conceptual systems mapping (CCM) and scenario practice for framing and visioning to structure evaluation. Such a participatory process can be conceived as an iterative cycle in four stages that include participatory framing (or re-framing) to jointly define a system of interest within a problem space and to understand which variables and relationships may matter most and how boundaries might be drawn; assessment; participatory evaluation; and synthesis, leading to a new round of reframing (see Figure 1.2). These stages, however, are not as cleanly separated in time in practice as suggested by this figure, but rather are overlapping and non-linear as they occur in time. Requisites to such knowledge co-creation processes are that they embrace (i) complexity by directing attention to the relationships between different parts of a system and engaging diverse disciplines, including critical and challengedriven inquiry across the natural, social, and engineering sciences (see Chapters 3 , 4 , and 5); (ii) contingency by connecting theory and practice and drawing on and producing place-based knowledge - local and very diverse forms of knowledge count, as well as knowledge about different viewpoints of the present and possible future worlds (Chapter 6); (iii) contradictions and trade-offs by taking an actororiented perspective; and (iv) uncertainty and ignorance (see also Chapter 16 and the postscript by Jerome Ravetz). Concepts further differentiating uncertainty, such 


\section{Ariane König}

as 'technical' and 'methodological' uncertainty, as in the NUSAP system (Chapter 16, Funtowicz \& Ravetz, 1990; van der Sluis, 2005), are deemed important so as not to entirely lose sight of what we don't know in terms of known and unknown unknowns. 'Ignorance', for example, can refer both to external realities and to our self-awareness. The distinction between 'surprise' (discovering unknown unknowns) and 'denial' (after Freud, refusing to be aware of the known) are also very useful. All such concepts are highly effective for analysing the states of knowing and knowledge, and of non-knowing and non-knowledge, that occur in meeting sustainability challenges and will be deployed where appropriate through the book.

The ambition of embracing complexity will often also facilitate directing attention to and deliberating what we do not know. The idea of 'complexity' has many roots in practice and many approaches. In this book, we present complex systems as a structured view of parts of a bounded whole that is developed for the purpose of investigating relationships between the parts. The structure of a system is designed as a function of the purpose of the analysis. Where to draw the system boundary for study is the first task of any inquiry; it depends partly on the complex system that the inquiry is part of in itself. Uncertainty is present to all degrees, and there is no privileged perspective among participants (see also Ravetz, 2006, and Chapters 3, 4, and 5 , and the postscript). The focus on relationships with possible time delays will call into question many simplified models developed for the purpose of close investigation of specific cause-effect relations, in a particular sub-system at a particular scale such as the economy, an ecosystem, or a particular cell. Adopting a systems perspective whilst acknowledging uncertainty enables gaining an integrated understanding and repertoire of action on situated problems. Quality assurance is a key concern in these new approaches to knowledge production (Funtowicz \& Ravetz, 2015; Haklay, 2015).

\section{What knowledge for sustainability?}

The procedural view of sustainability science developed in this book stems from a pragmatic philosophical perspective on science, technology, and knowledge. It presents questions on what it might mean to 'integrate' learning, research, and practice for the purpose of gaining an integrated understanding by drawing on insights from different theory and research approaches that have emerged from disparate disciplines.

The philosophical perspective of pragmatism further invites us to reconsider the relation of the human mind with the universe, not as representational but as causal. The languages and symbols we use to evoke reactions and convey meanings are not pictures of reality, but are rather part of the causal network that bind humans to their environment - tools of an intelligent animal. According to Richard Rorty and others, knowledge resides in interaction with others and the environment and in the contemplation thereof. It is fluid and dynamic; it is the basis for our beliefs, which we then make explicit in their justifications. Knowledge is simply what we are justified in believing, and justification is a social/relational phenomenon. Pragmatism seeks to avoid confusion between 'the human justification of knowledge claims' and 'causality in reality'. Pragmatists replace the 'appearance'/'reality' distinction with descriptions of ourselves and the environment that are 'more or less useful'. Similarly, science is conceived as not serving to represent, but rather 
to manage realities. And according to Rorty, 'the purpose of inquiry is to achieve agreement of what to do, with what end, by what means to make life better - any other inquiry is just word play'. Accordingly, the quality of science is revealed in its power on how to make life better (Rorty, 1999).

In this book, it is assumed that the more we are aware of and embrace the culture-technology-environment connection in our knowledge co-creation processes, the more successfully we will be able to transform prevailing ways of thinking and doing to make them sustainable. Technology, which significantly contributes in shaping human-environment interactions, can be seen as an expression of not only scientific knowledge, but also the prevailing cultural beliefs and worldviews that shape our relation to nature (see, for example, Parodi, 2008, p. 15; Dyball \& Newell, 2015). In fact, technology is shaped by but also contributes to changing prevailing values and worldviews.

Building on Sir Geoffrey Vickers's work (1984) investigating the relation between (scientific) theory and practice in an 'appreciative setting', we distinguish three dimensions of judgments in societal deliberative processes that are to lead to more fundamental changes in prevailing social practice in the form of more stable norms and customs. He describes 'appreciation' as a deliberative process by which judgments are formalized in diverse groups of scientists and stakeholders. Accordingly, building on Vickers and Burt and van der Heijden (2008), we distinguish three types of knowledge that appreciative judgments are based on that will influence changes in social practice, technological innovation, and shared expectations and notions of progress that guide these changes:

(1) Knowledge on perceived realities requiring an understanding of humanenvironment relations as complex dynamic systems;

(2) Knowledge on values defended by diverse individuals and groups, from which a direction or purpose can be deduced and which can also present grounds for conflicts, contestation, and polarization to the extent of blocking learning and decision making in value pluralist societies; knowledge on values also facilitates cognitive switching and building empathy by looking at challenges from diverse perspectives;

(3) Knowledge for action, or 'actionable knowledge', which combines the two previous sets of knowledge to arrive at judgments on socially robust and acceptable and desirable courses of action, with insights on the functioning of organizations and institutions as sedimented forms of social practice that may pose barriers to change or lock-ins of undesirable practices and some strategic insights on how these might be overcome.

In line with Armin Grunwald's research on understanding sustainability (Grunwald, 2016), we add a fourth type:

(4) Knowledge about emergent futures, which can be gained from participation in participatory scenario approaches and visioning practices, which conveys a sense of shared imaginaries about the future (see also Jasanoff, 2015), together with their social robustness in terms of their aggregate desirability, acceptability, and plausibility. Joint deliberation on alternative futures also helps to make explicit uncertainties, areas of ignorance, and potentially disruptive events. 


\section{Ariane König}

Such knowledge also helps cognitive switching between past, present, and alternative future worlds. The question of 'How can the future be scanned in a creative, rigorous, and policy-relevant manner that reflects the normative character of sustainability and incorporates different perspectives' is critical in seeking reorientation in discussions on the meaning of progress and development trajectories (Grunwald, 2011; Swart et al., 2004; Robinson et al., 2011). The conception of transformative sustainability science of this book offers a process that allows the emergence and explicit deliberations on these four forms of knowledge (see Figure 1.3), and to draw on all four to gain an integrated understanding of the complexity of the issues and socially robust courses of action from them (König, Chapter 19). Core research questions that prevail in transformative sustainability science are concerned with better understanding from diverse stakeholder perspectives what is 'actionable knowledge' and further improving methods for stakeholder interaction and learning to change their social practices with methods such as systems thinking and alternative futures. They explore the design of more interactive processes that enable the exploration of highly complex and uncertain value-laden issues and

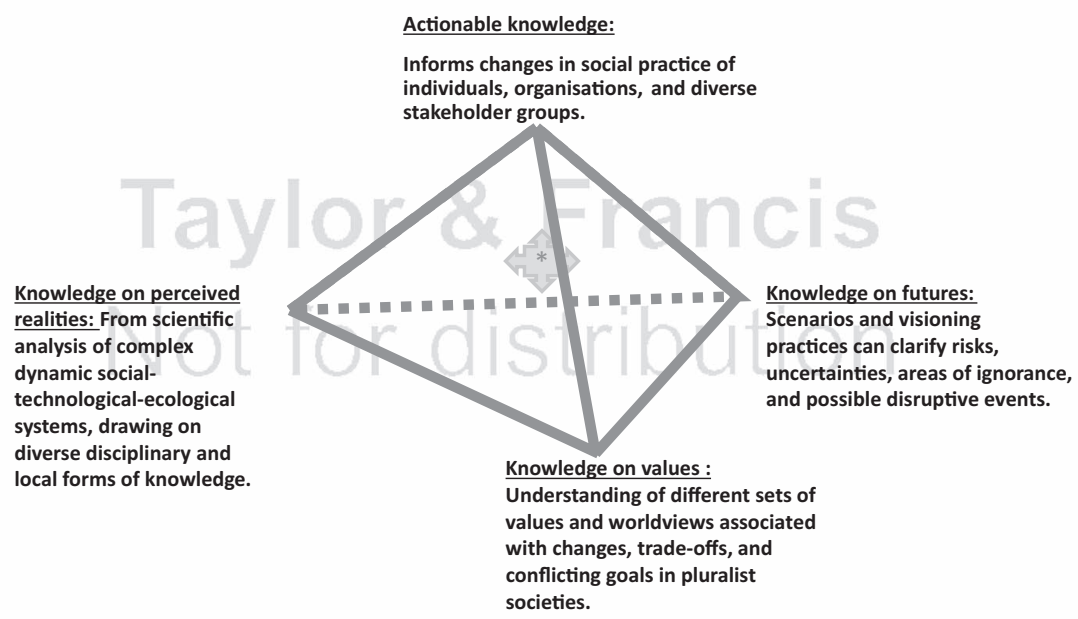

*Process for co-creation of four knowledge types: Relies on rigorous participatory scientific inquiry and quality control.

Figure 1.3 Four knowledge types in transformative sustainability science

Knowledge on perceived realities: From scientific analysis of complex dynamic socialtechnological-ecological systems, drawing on diverse disciplinary and local forms of knowledge.

Knowledge on values: Understanding different sets of values and worldviews associated with changes, trade-offs, and conflicting goals in pluralist societies.

Knowledge on futures: Imagined futures serve to motivate change in the present. Scenario practices can clarify risks, uncertainties, areas of ignorance and possible disruptive events, and alternative possible futures and their trade-offs. A vision provides a desirable future that can help orientation and concerted action in diverse groups; it is normative.

Actionable knowledge: Informs changes in social practice of individuals, organizations, and diverse stakeholder groups. 
bring these processes closer to social learning and action in real life (Robinson et al., 2011; König, 2013, 2015; Wiek \& Lang, 2015; but also Dyball \& Newell, 2015; and Newell and Siri, 2016). One further essential challenge remains: to understand and try to track social change that allows for the emergence of new forms of production, consumption, and distribution with new forms of combinations of technologies, organization, institutions, and lifestyles (Jerneck et al., 2011).This will require directing more attention to how new knowledge, science, and technologies are actually co-produced with social practice that is then stabilized in the form of social values, norms, rules, and institutions (Jasanoff, 2003; Jasanoff, 2015).

Transformative sustainability science can thus also be understood as a transformative social learning process, which relies on scientific inquiry in diverse groups of stakeholders and experts. The relation of learning across different scales of social organization matters (Wals et al., 2014). Conceptions of social learning in environmental management and human ecology are closely aligned and suitable to build upon in further developing conceptions of transformative sustainability science (Keen et al., 2005; Dyball \& Newell, 2015). This conception of learning is rooted in John Dewey's work (1938), who argues that knowledge is constructed for action and that learning can be mediated by iterative cycles of making an hypothesis, systematic inquiry testing hypotheses in practice, observation, and reflection. Transformative learning then emerges from dialogue between groups with diverse sets of values and worldviews, in which each group is brought to reflect on and creatively re-consider their own ways of thinking and doing (Lotz-Sisitka et al., 2015) (see Section 1.4). There is an interesting convergence in the literatures on procedural requisites for transformative sustainability science and social learning, or transformative social learning for sustainability (Peters \& Wals, 2013; Wals et al., 2014). Understanding diverse facets of challenges from distinct perspectives of different experts and stakeholders who engage in transformative social learning from each other is deemed necessary to better understand complexity (Wals et al., 2014; Newell \& Doll, 2015; Dyball \& Newell, 2015).

\section{Why sustainability science may be seen as problematic}

Associating the concept of sustainability with science raises a number of problems. First, the concept of sustainability is normative, as it suggests a direction in terms of 'good' or 'bad' ways in which society and environment interact. Furthermore, a focus on the human-nature interface requires us to embrace complexity, in the diversity of perspectives and commitments; situated knowledge, rather than abstract scientific knowledge that is expressed in formulae or models that claim universal validity; contradictions associated with contested expertise and interests; uncertainty; and ignorance. This is at odds with the social norms widely associated with science, including 'disinterestedness' and 'universalism' (Merton, 1973). Because these norms are still very much the basis for determining 'excellence' through peer review, they are then in turn reflected in terms of career rewards, even survival, in research organisations.

Building on Thomas Kuhn's observations of science as a social institution, most of 'normal science' that is conducted within disciplined groups of scientists can be seen to focus attention on the exclusive study of a tightly specified system, at specific spatial and temporal scales. Further it is customary in most disciplined fields to build on assumptions that reduce complexity, uncertainties, and value pluralism. 


\section{Ariane König}

Quality criteria in most disciplines drive towards abstract and generalizable knowledge that claims quasi-universal validity, rather than situated knowledge that takes account of local contexts. Kuhn also points out that science education often implicitly conveys and enforces specific sets of beliefs and worldviews. Both education and research practice rely on review and reward systems that can systematically suppress disagreement, contradictions, and dissenting views. Kuhn refers to a situation when "the profession can no longer evade anomalies" (Kuhn, 1962, p. 6). The resulting fragmentation of fields of knowledge impedes the sense-making of complex systems, which are the matter of sustainability science. This phenomenon of fragmentation of disciplinary knowledge fields from the drive to further specialization also has the effect of undermining quality control through peer review, even in the most 'normal' of sciences. This problem is now publicly acknowledged, as we now see with the 'reproducibility crisis' in the natural and social sciences and 'endarkenment' in the humanities (Millgram, 2015).

Kuhn has demonstrated the inadequacy of his 'normal science' for engaging with the problems of the complex world of sustainability. He says (Kuhn, 1962, p. 37)

It is no criterion of goodness in a puzzle that its outcome be intrinsically interesting or important. On the contrary, the really pressing problems - such as, a cure for cancer or the design of a lasting peace - are often not puzzles at all, largely because they may not have a solution ... A paradigm can, for that matter, even insulate the community from those socially important problems that are not reducible to the puzzle form, because they cannot be stated in terms of the conceptual and instrumental tools the paradigm supplies.

Building on these insights, 'Post-Normal Science' (PNS) was the first conceptualization that explicitly introduced uncertainty and value loading into the description of a type of scientific practice related to policy (Funtowicz \& Ravetz, 1993). It introduced an element of democratization of science (see also Chapter 2 by Wals and Michaels) in the mention of the 'extended peer community'. As the concept evolved, complexity was incorporated into the scheme. Because most scientific practice, and all science education, is still 'normal' in Kuhn's sense of puzzle solving, PNS still has a very useful function as the first step in understanding the position and role of science in the contemporary world. It can also lead towards the comprehensive vision of sustainability science.

However, the classification of sustainability science in relation to 'normal' disciplinary fields of knowledge remains virtually impossible, for a defining attribute of sustainability science is that it draws from and builds on theory, methods, and practice of a wide range of sciences. Professional identities of scientists and the roles they play in society are conceived quite differently, depending on the fundamental worldviews in the various disciplines. This is reflected in distinct understandings of what science is, from whence it derives its authority and legitimacy, and how it is done. Furthermore, the quality of an 'integrated process or understanding' that is derived from drawing on diverse fields of knowledge cannot be judged based on criteria or review procedures from any single one of the relevant fields. Issues of quality criteria and processes are hence of central concern in sustainability science (Funtowicz \& Ravetz, 2015).

Normal and post-normal science now need supplementing with another that we describe as 'transformative sustainability science'. Transformative sustainability science is a social process that draws on methods and practices to structure and systematize knowledge creation from diverse disciplines, as well as from other types 
of knowledge, including diverse forms of local knowledge. Participatory environmental sensing and sense-making technologies and virtual spaces on the Internet that are now fashioned for co-creative scientific inquiry in citizen science projects, such virtual spaces open up significant opportunities for scaling certain dimensions of transformative sustainability science. It also adds new spaces for shared representations for join 'reflection' in such knowledge co-creation processes.

For the previously mentioned reasons, including the current lack of established methods for quality control, it is very challenging to establish sustainability science initiatives in more traditionally oriented research organisations. Systemic change in the university system and in prevailing ways to practice and legitimise science is therefore at the core of any strategy to foster and catalyse sustainability scienceinformed transformations in society at large (Sterling, 2013; Barth, 2015; Schneidewind et al., 2016).

\section{Sustainability science: diversity of purpose and approaches}

The possibility of juxtaposing different ways of describing problems and different ways of knowing helps to identify knowledge gaps and dissonances. This can contribute to a better understanding of how different facets of complex problems might be related to each other and acted upon, and thereby may open up creative new perspectives. Meanings of 'sustainability' that shape what 'purpose' is seen for sustainability science usually depend on the local context and people involved in addressing a specific challenge, such as water scarcity that can also affect local food production and electricity generation. This often also depends on diverse conceptions of actors and agency, which in turn affect more normative ideas on 'action fields and who the main actors are' that can emerge from such research (O'Brien, 2012; O'Brien, 2015).

Four broad discourses can be distinguished in academia (although this is by no means an exhaustive list) that have all different interpretations about meanings of sustainability and purpose of sustainability science. (Chapter 3 by König, comparing diverse systems approaches, provides a similar and more detailed comparison of how different disciplines direct attention to different problem framings and solution approaches). Research in environmental and earth system sciences that has gained great attention from policy makers worldwide aims to better understand the range of natural variation in, and anthropogenic impacts on, the earth system in order to deduce global and regional 'boundaries' or limits to human activities that should be respected (Rockström et al., 2009; Steffen et al., 2015). Some scholars from the field of economics are usually interested in problems of, 'internalizing externalities', for example by accounting for environmental damages caused in the production of goods and provision of services in pricing them, such that prices more appropriately reflect these 'externalities' in terms of collateral damages caused (Costanza et al., 2014). Other economists focus on conditions of 'market failure', as in the case of 'tragedy of the commons'. This tragedy describes conditions and types of goods and services to which basic market rules governing supply and demand of more typical goods do not apply. In these cases, groups of users may self-organize for sustainable management of vulnerable resources stocks, as is the case for management of the commons, including public forests, fish stocks, or ground water basins (Ostrom, 2009). By contrast engineering and urban planning often focus more on the technological dimension, engaging in discourses of ecological modernization, such as how public investment and market forces may be improved to reduce pollution at its source (Hajer, 1995). In philosophy and the learning sciences, the advocates 
of deep ecology argue that we require profound changes in human consciousness about our relations to nature (including non-human animals) and to each other. In consequence, the goal is not to be 'doing things better', but instead to be 'doing better things' (Peters \& Wals, 2013). Last but not least, some researchers fear change may come too slowly in the absence of urgent crisis. This perspective of impending 'Doom' is often the basis for research on resilience and adaptive management in crisis.

Research approaches associated with such diverse worldviews differ profoundly. They include disciplinary, interdisciplinary, or trans-disciplinary projects conducted by scientists alone or in collaborative processes with stakeholders, or are embedded in practice. Systems of interest include nature, society, or technology, at any scale. Research may be concerned with natural systems and planetary boundaries of the earth system or more concerned with social systems, problematizing actors and agency, and how sets of human values can serve as ordering principles in society (Castree, 2015). Research may be designed to better understand or to transform interactions between these systems. Ways of knowing can be conceived as inductive or deductive language-based reasoning, or knowledge can be seen as emergent from interactions between people and their environment, through practice or experience. Many research projects are aimed at the 'integration' across disciplines. Given very different sets of assumptions that shape concepts and methods used in different fields, this can, however, be a somewhat nonsensical endeavour. Armin Grunwald carefully discusses the challenges to and meaning of 'integration' in such 'integrative research projects' (Grunwald, 2016).

\section{Sustainability science as a transformative social learning process}

Transformative sustainability science can also be understood as a transformative social learning process that relies on scientific inquiry in diverse groups of experts and stakeholders (Peters \& Wals, 2013; Wals et al., 2014; König, 2015). The process needs guidance and a safe space to ensure that everyone engaged is prepared to juxtapose diverse perspectives and to question their own assumptions. The relation of learning across different scales of social organization matters (Wals et al., 2014), building on prevailing conceptions of social learning in environmental management and human ecology (Keen et al., 2005; Dyball \& Newell, 2015). The conception of learning advanced in this book is rooted in John Dewey's work (1938), who assumes that knowledge is constructed for action and that learning can be mediated by iterative cycles of making hypotheses, systematic inquiry testing hypotheses in practice, observation, and reflection.

In the face of scarce or damaged environmental resources, social learning is a form of social coordination that is more effective in translating research findings into real-world coping mechanisms than either hierarchical government regulation or market competition (see Table 1.1). Physical, technological, and social infrastructures for supporting the institutionalization of such community self-governance processes are key for their effectiveness. Platforms for analytic deliberation to deal with value conflicts are required (Dietz et al., 2003; Ison et al., 2007). Social learning focuses on the relation of learning across different scales of social organization: individual, group, organizational, or societal (Medema et al., 2014; Wals et al., 2014). Building on this research, learning is conceived of in this book as a process of developing enriched understandings and repertoires of action on complex problems as 
Table 1.1 Forms of social coordination

\begin{tabular}{|c|c|c|c|}
\hline Social coordination & Actors & Form of knowing & $\begin{array}{l}\text { Taking account of complexity, } \\
\text { uncertainty, management of } \\
\text { commons }\end{array}$ \\
\hline $\begin{array}{l}\text { Regulation } \\
\text { Education } \\
\text { (hierarchical) }\end{array}$ & Government & $\begin{array}{l}\text { Fixed form applied to } \\
\text { a defined problem }\end{array}$ & $\mathrm{X}$ \\
\hline $\begin{array}{l}\text { Market-based } \\
\text { Competition } \\
\text { (individualistic) }\end{array}$ & $\begin{array}{l}\text { Firms and } \\
\text { consumers }\end{array}$ & $\begin{array}{l}\text { Fixed form applied to } \\
\text { a defined problem }\end{array}$ & $\mathrm{X}$ \\
\hline $\begin{array}{l}\text { Social learning } \\
\text { (Non-coercive, } \\
\text { egalitarian) }\end{array}$ & $\begin{array}{l}\text { All stakeholders } \\
\text { in a resource }\end{array}$ & & $\begin{array}{l}\text { - Iterative learning } \\
\text { process towards shared } \\
\text { understanding of a } \\
\text { dynamic complex } \\
\text { unknowable situation } \\
\text { - Shared learning serves } \\
\text { as basis for concerted } \\
\text { action } \\
\text { - Solutions are emerged } \\
\text { properties of the social } \\
\text { process }\end{array}$ \\
\hline
\end{tabular}

a result of open and iterative cycles of experimentation, observation, analysis, and judgment of results. The fact of knowing more and mastering knowledge in a different manner through experimentation, reflection and continual learning changes our relationship between the world and ourselves.

Reasons for the prevalence of particular ways to organize knowledge and learning include the ways we perceive our brain to function; how we learn to make conceptual representations in our minds, including of our identity and our surroundings; and how we manage our emotions and creativity. Sense-making can be seen as a process of matching perceptions to accumulated embodied experiences, which are organized in our minds with conceptual representations of our surroundings. These concepts can pre-structure and thus filter what we perceive and experience. As we learn, these conceptual representations can also be iteratively adapted or changed based on personal experiences from interactions with our physical and social surroundings that do not match previous organization in our mind. Hence, situations in which different groups of stakeholders consider disparate truths as self-evident can arise when each group relates the problems that are discussed to entirely different conceptual environments, considering problems at different scales and time frames. For example, even within the field of biology, molecular biologists and ecologists will often disagree whether genetically modified organisms present acceptable risks in agricultural or other industrial applications.

Stated goals of some collaborative projects to gain an integrated understanding from diverse perspectives on one system may therefore be hampered at the conceptual level. This is usually evidenced in many time-consuming and eventually failed attempts to develop common, precise, language-based definitions for key terminology to describe and structure a problem. Consequently, some collaborations just avoid the feat of developing shared sharp definitions; this, however, can 
prevent effective shared understanding and communication of new shared insights, in particular, if the main vehicle for sharing and exchanging perspectives remains just technical language (Newell \& Proust, 2012). Language does not automatically convey meaning, as words stripped from their context do not convey meaning (Reddy, 1993). The use of metaphors, indicators, and pictures to link new conceptual representations to particular embodied experiences help to open new doors of perception, transformative learning, and new realities to be discovered and stabilized in our minds (Newell \& Proust, 2012; Newell, 2012). This insight builds on research in cognitive linguistics, which posits metaphor as a logic-preserving mapping from concrete experiences to abstract concepts (Lakoff \& Johnson, 1980). Once the limitations of language are recognised, efforts can be made to develop more powerful ways of communicating.

Accordingly, we infer that collaborative inquiry about complex systems performed in diverse groups can foster the emergence of new related phenomena, as expectations in participants change, at times converge, and become stabilized in changes in social practices and structures (König, 2015). Progress then can build on the evaluation of and passing judgment on a direction of development. Related competences to be developed in education for sustainability include systems thinking to embrace complexity and normative capacities to better understand diverse sets of values and worldviews in order to gain an enhanced judgment of courses of action deemed acceptable and feasible by many (Wiek et al., 2011).

This learning requires different conceptions of teaching and learning environments (see Table 1.2) from traditional approaches to teaching that still prevail - at least in most of higher education.

Research on learning processes identified citizen science-based community monitoring projects as an effective means to learn to improve natural resource governance in a range of diverse stakeholder groups and settings (Wals et al., 2014). Citizen science is 'scientific work undertaken by members of the public, often in collaboration with or under the direction of professional scientists' (Oxford English Dictionary, 2014). Public participation in scientific research can take diverse forms, ranging from

Table 1.2 Comparative table of two cultures of learning

\begin{tabular}{|c|c|c|}
\hline & Transmissive learning & Transformative learning \\
\hline $\begin{array}{l}\text { Purpose and } \\
\text { Scope }\end{array}$ & $\begin{array}{l}\text { Understand defined cause } \\
\text { and effect relationships }\end{array}$ & $\begin{array}{l}\text { Personal transformation in contribution to } \\
\text { systemic change }\end{array}$ \\
\hline Process & $\begin{array}{l}\text { Transfer of information } \\
\text { from experts }\end{array}$ & Action-oriented development process \\
\hline Teaching & Teacher defines meaning & $\begin{array}{l}\text { Teaching facilitates negotiation and } \\
\text { construction of meaning in diverse groups }\end{array}$ \\
\hline $\begin{array}{l}\text { Learning } \\
\text { Environments }\end{array}$ & Classroom or laboratory & $\begin{array}{l}\text { Emergence of new knowledge from } \\
\text { interaction with complex real-world } \\
\text { learning environments in diverse groups }\end{array}$ \\
\hline $\begin{array}{l}\text { Outcomes and } \\
\text { Impacts }\end{array}$ & Efficient reproduction & $\begin{array}{l}\text { Shared actionable knowledge, transformed } \\
\text { perspectives, and environments }\end{array}$ \\
\hline $\begin{array}{l}\text { Assessment and } \\
\text { Evaluation }\end{array}$ & Standardized testing & Self-evaluation and critical support \\
\hline
\end{tabular}

Source: Adapted from König, 2015b

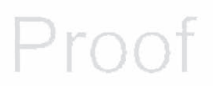


scientists soliciting passive sensing activities or brain power from volunteers, to fully collaborative projects, in which citizens engage in problem framing, research design, observation, analysis, and interpretation (Haklay, 2015). Haklay defines the form of 'extreme' citizen science practiced by his research group as 'a situated, bottom-up practice that takes into account local needs, practices and culture and works with broad networks of people to design and build new devices and knowledge creation processes that can transform the world'. ${ }^{1}$ Accelerating innovation in cheap sensor technologies, mobile computing tools, networking applications, and data aggregation and processing tools allows for crafting rich user interfaces and the storing and sending of time- and location-tagged data. Flexible open-source software tools that are easily adapted for diverse monitoring purposes to combine sensor-derived data, photographs, and the input of subjective data on environmental quality allow usage by citizens and researchers with little computing knowledge (Stevens et al., 2014).

Empirical evidence suggests that participatory monitoring projects can transform the relationship of ecosystems, local communities, and economies; reconnect people to the landscape and to each other; and achieve appreciation of complexity and renegotiation of what and how values are attributed in the community (FernandezGimenez et al., 2008). Chapter 14 describes the beginnings of citizen science in the developing world for improved water governance. In the EU, several citizen science projects and citizen observatories, including one on flooding and a coordination platform, were financed under FP7 and the Horizon 2020 framework programme and the EU Digital Unit of the European Commission. The first eco-schools are adopting citizen science inquiry-based approaches to combine learning with the staging of community environmental projects (Hargreaves, 2008). And during the Obama administration in September 2015 a communication from John Holdren, the Director of the White House Office for Science and Technology Policy and Chief Science Advisor to the president, even invited all federal agencies to prepare for soliciting data for evidence-based policy making, including environmental monitoring data from new approaches to crowdsourcing and citizen science. Chapter 2 introduces reasons for the urgency to foster the combination of transformative learning from and with civic and citizen science in an era of post-truth politics stabilised by the Trump government in the United States. Citizen science projects can be designed as environments in which transformative learning for changing social practices across scales of social organisation takes place. These designs can include conceptual tools and associated social processes presented in Part I of this book, including systems, futures, social technologies, and human-centred design thinking. A recent project that exemplifies a research design based on these insights is starting in Luxembourg in 2017 and is described in more detail in this book's conclusion.

\section{What systemic transformation?}

Systemic transformation first relies on the emergence of new social practices. These in turn can be consolidated into new social structures such as institutions and prevailing sets of rules, social norms, and values. Systemic transformation for sustainability requires new forms and logics of collaboration. In systemic change, there is a complementarity of the changes at the individual level in terms of attributing new meaning and the various social levels. It is therefore helpful to consider the characteristic patterns of change at both levels (see also Chapter 16 by Manhart).

Individual meaning-making is linked to perceptions, conceptual representations, and experiences and expectations. Embodied experiences are matched to

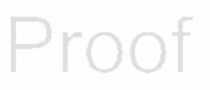


conceptual representations in one's mind, and these are continuously and iteratively changed to accommodate these experiences. And the iteratively refined conceptual representations in turn serve as filters to pre-structure subsequent perceptions. Transformative learning will result in a reframing and reconfiguration of those perceptions, conceptions, experiences, and expectations. This can more fundamentally change how we relate these to each other within ourselves and in dialogue with others. For these functions, the language is not merely descriptive and analytical, but it will also rely on metaphors (Newell, 2012, citing Lakoff, 1980). Beyond that, other vehicles for meaning will be used, including graphic representations of quantities, along with drama, music, and art. These can include diagrammatic techniques used in the approaches to low-order conceptual systems mapping described in this book (Newell and Proust, Chapter 5), which describe how we can step by step establish a shared visual language on which aspects of complex challenges may matter most from diverse perspectives as a basis from which to use focused dialogue to develop well-defined conceptual/theoretical frameworks. This is one of many evolving approaches and methods for making connections and creating new ways to arrive at shared perceptions, experiences, and concepts to allow the reframing and reconfiguration of the experienced reality.

The complementary level of transformation, the social, will require creativity resulting in entirely new expectations and their associated social practices and technologies (see also Chapter 16 by Manhart). Moreover, these new social practices must emerge from, and be fit for, the dynamic networked society of the future rather than the hierarchical industrial society of the past. Radically new concepts of knowledge and learning, and associated social processes and spaces, are required, and digital technologies have a role to play (Wegerif, 2007). The emerging generations just born in this new millennium, who seem to spend more time and thus gain more experiences in the networked virtual space, may engage in meaning-making not so much by relating concepts to embodied experiences from interacting in and with the physical world, but by seeking and comparing different perspectives from the virtual space. This can be much more pluralist and rely on cognitive switching between diverse perspectives. This is the perspective of the 'global village' first articulated by Marshall McLuhan, where diversity of customs, assumptions, and values is a familiar experience to citizens. When the practice of meaning-making is more sensitive to highly divergent assumptions of what constitutes a reality and how it may be experienced, new possibilities for systems approaches and new creative solutions may emerge. Knowledge gaps and contradictions may become more easily apparent and less troubling to embrace, and these can present spaces for creativity (Wegerif, 2007).A serious challenge here is the requisite for new types of quality assurance for legitimating and protecting this emerging new shared knowledge.

Contemplation of such a far-reaching transformation of society and consciousness might seem to be ambitious to the point of being utopian. But such transformations occur regularly in the history of civilisations. In Europe, we have three well-marked epochs in the cultural dimension that we call 'medieval', 'renaissance', and 'modern'; and in the technological and economic dimensions we have 'industrialisation' and 'capitalism'. We have even witnessed an attempted transformation that, at least in the short to medium term, has largely failed, namely 'socialism'. In each case there were, or were intended to be, profound transformations in some crucial aspect of social or cultural life at social and individual levels. Much of the deep theoretical reflection on society has been stimulated by the challenges and contradictions that were witnessed in the replacement of one epoch by another. 
The pace and pattern of transformation to a new social-cultural order cannot be predicted, but there are many indicators of a rapid change in the style of social behaviour along lines towards co-creation. A mere century ago discrimination based on race was generally considered to be only right and natural in many societies. Arguably, Rachel Carson's book, The Silent Spring, and photos of planet Earth from outer space contributed to transforming our sense of 'the environment'. Such transformations will be complex and partial, and many practices that violate nowestablished normative concepts such as equity and environmental protection persist unchecked. But a direction can be discerned.

Decisions on alternative paths of action invited by just-discernible changes in social norms, however, are not often obvious, and what is considered obviously 'good' from one perspective can be considered 'an evil threat' from another. For some individuals, they promise liberation and self-realisation; for others, they threaten a loss of integrity and livelihood. Institutions that are endangered will respond with all possible means. 'Good' causes and campaigns can be caught up in power struggles in which they are mere pawns and risk corruption or extinction. Campaigns for practices for environmental protection at a very local level have the potential to 'harm' some people and their environment.

A genuine education for transformation will prepare participants for such complexities and contradictions. Practicing putting yourself in other people's shoes is crucial to recognise why some people or institutions opposing such change may just be selfish or reactionary. People have the right to fundamentally disagree about what is good and in relation to the facts, the right to be wrong. For such leaders as Martin Luther King and Nelson Mandela, dialogue with malevolent opponents did not come easily; but they knew that that is the only true path to systemic transformation (see Chapter 6 on scenarios).

How can transformation through the creation of new shared meanings and expectations be achieved? As stated earlier (Section 1.1.1., Figure 1.2) sustainability science conceived as a transformative social learning process will have four main procedural attributes it helps to embrace: (i) complexity, by adopting a systems perspective and developing the practice of cognitive switching between diverse perspectives for meaning-making; (ii) contradictions and learning to dialogue for collaboration across different worldviews; (iii) contingency and the need to produce situated knowledge in a systematic manner; and (iv) recognising gaps, unknowns, and ignorance for making creative spaces that enable new ways of seeing and new social practices. Last but not least in this era of accelerating change, we need to learn a new way to relate to the past, present, and future. These are fundamental requisites for transformational change.

\section{Judging transformative learning}

Transformative learning will be assessed based on observable changes in communication and behaviour by individuals and organizations over time. One approach is to define and access relevant competences, usually identified as systems thinking, a future orientation, and normative competences (Wiek et al., 2011). The content of learning may also be assessed based on Vickers's (1984) conception of appreciation of complex systems in three dimensions: reality judgement that is reflected in the enriched systems understanding; value judgement relating to perception of the diversity of values and worldviews; and instrumental judgement on which actions may be acceptable and feasible to diverse stakeholders. Another approach is 


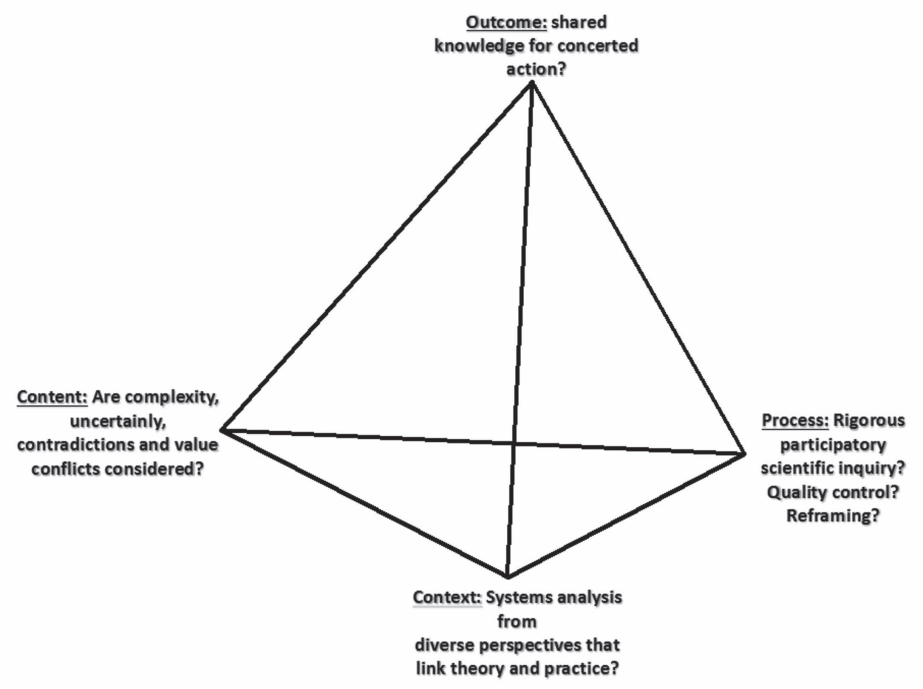

Figure 1.4 Evaluation questions for transformative sustainability science

to seek to track empowerment through education (as described by Wals and Peters in Chapter 2). The assessment of creative thinking in diverse groups can be assessed simply by observing the types of dialogue they engage in (Wegerif et al., 2015). Three types of talks are distinguished, disputational, cumulative, and exploratory talk, in order to observe how participants enter into dialogue in group interviews and workshops.

Apart from observations of transformative learning at the individual and organizational level, the evaluation of impacts and outcomes of transformative sustainability science is a complex field. This would require the evaluation of the quality of the social process for knowledge co-creation, as well as the evaluation of visible changes that may have been affected through the process, such as changes in behaviour and communication; institutions; material and energy stocks and flows of natural and anthropognic nature; and the mergence of new technologies, or new uses or users. There is an important and growing literature on quality criteria and the evaluation of transformative sustainability science, which is beyond the scope of this chapter, but in part is addressed in Chapters 14 to 18 .

\section{Structure of the book}

In order to provide guidance and resources for capacity building in communities of scientists and citizens to engage in transformative sustainability science, we have divided this book into three parts. Each chapter in these parts offers a reflective account of a particular challenge, an approach by which these challenges can be explored, a critical discussion of the merits and limitations of the approach, and a conclusion on the significance of the insights gained. All contributors have been 
encouraged to state their assumptions in theory and methods they refer to as well as personal convictions and motivations to engage in their research or profession. These are requisites to allow for critical inter-disciplinarity, which directs attention to limitations and contradictions between specific disciplinary approaches to generating new knowledge. Because this book records experiments in a new methodology, a fully matured, critical inter-disciplinarity is not always achieved. In sum, the book equips readers with a better understanding of how one might actively design, engage in, and guide processes by which society and the environment interact.

The second chapter of the introductory part, Chapter 2 by Arjen E.J. Wals, a learning scientist, and Michael Peters, a political philosopher, builds on John Dewey's sense that 'the cure for ailments in democracy, is more democracy'. Risks of coercive forms of sustainability implemented by elite 'expert-driven' technocratic governments, based on top-down goals and indicators, and counter-movements supporting post-truth politics, are to be countered by combining education and transformative social learning with collaborative inquiry in civic and citizen science projects. Recent insights on necessary changes in how we conceive of research excellence and education in academia and policy making are critically discussed. The organisation of knowledge co-creation should take into account concerns of social fractures and risks of reinforcing inequity. The importance of developing spaces and education for transgressive thought that questions existing orders and boundaries is highlighted, without which no democracy can learn to live up to the promises of the democratic principles across changes in time.

\section{Part I: Embracing complexity and alternative futures: conceptual tools and methods}

Part I provides an overview on diverse conceptual tools and methods that are useful in structuring transformative social learning processes that draw on diverse types of expertise and practical experience. These methods are required to collectively question prevailing knowledge and problem framings and reframe the issues to adapt them to different contexts.

The first three chapters focus and provide ways to overcome our own limitations in the face of complexity in dynamic social-technological-ecological systems that are rooted in the ways our human brains function, but also in our education system that generally reinforces breaking down complexity into too simple direct causeeffect relations. Chapter 3 by Ariane König discusses diverse approaches to conceptualise human-environment interactions as embedded in complex and dynamic social-ecological systems, in which interactions between different elements in the system play a greater role in determining the behaviour of the overall system than do interactions within the different sub-parts of the system. Chapter 4 by Philipp Sonnleitner, a cognitive psychologist, starts by describing cognitive challenges in the face of complexity. Self-reflection on personal emotions in this process is an important dimension of the learning experience. In-class exchanges on different cognitive approaches and emotional responses in the face of complexity are also important learning dimensions in order to build the empathy required to work in diverse groups on complex problems. Chapter 5 by Barry Newell and Katrina Proust provides guidance on how to implement a step-by-step process to characterise what matters most in complex, dynamic human-environment systems in 
diverse groups. This approach to Collaborative Conceptual Modelling (CCM) of dynamic human-environment systems directs attention to interactions and feedbacks that shape overall patterns of behaviour within such systems. This enables groups to collectively decide which leverage points to address to develop feedbacks from policies and associated learning by design that counteract unsustainable trends. CCM approaches are usefully embedded in scenario approaches that allow the same groups to get a better understanding of drivers of change in the past, present, and future and what is certain and uncertain about these.

The next two chapters describe methods to explore and sense alternative futures in diverse groups. Chapter 6 by Gerard Drenth, Shirin Elahi, and Ariane König introduces the readers to participatory scenario approaches in order to better understand uncertainty in complex conditions and potential disruptive changes and human choice and constraints. The role of diverse imaginations of the future in deliberations and motivations to change current practices is uncontested. There are diverse methods to structure explorations of alternative futures. Exploratory scenarios are plausible stories describing future worlds that illustrate alternative outcomes of developments. The approach blends qualitative and quantitative analysis in order to explore alternative outcomes of global change and associated implications locally in the transactional environment, where some changes might be brought about if a critical mass of stakeholders engages. A set of scenarios usually serves to highlight things we can or can't know about the future; uncertainties that matter but are rarely talked about; and inter-dependencies in alternative future development paths, human choices and constraints, and differential power distribution in society. Sets of scenarios may also be designed to sketch the interdependence of culture and values prevailing in society and how these are interdependent with technological choices; this may also be related to experienced quality of life and environment and how distributional issues might play out in different futures. Visions, by contrast, offer a desirable future to serve as an orientation for concerted action in diverse groups - they are normative. Chapter 7 by Isabel Page introduces Theory U, a stepby-step approach to exploring the emerging future in diverse groups. It is necessary for transformational change for members of a group to relate to each other in different ways in order to suspend their own ideas, fears, and judgments. Then the group can enter a special space in which all identify with the problem and try to switch between diverse perspectives on this problem rather than defending their own viewpoints and interests. In that way they can conjointly sense the merging future possibilities that might be realized in collective action.

Chapter 8 by Kilian Gericke and Gregor Waltersdorfer introduces humancentred design thinking as one approach to structure processes to develop a particular form of 'actionable knowledge' as specific solutions to design problems that have been identified in scenario and conceptual systems mapping exercises. The iteration between ideation and prototyping following the motto of implementing, failing, learning, and improving fast is the core of this method.

\section{Part II: What might transformations look like? Sectoral challenges and interdependence}

The seven chapters in Part II ask what is transformed and how, both in theory and in practice, providing more disciplinary and sectoral perspectives on particular challenges of sustainability. We have taken care to draw on internationally salient issues and examples. Examples are taken from agriculture, energy use, and water

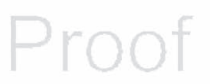


management. In each of these sectoral chapters we discuss changing prerequisites to scientific research and practice, as well as challenges and pitfalls in the discourses on change that are prevailing in Luxembourg, in the EU, and in other world areas, including in the developing world. In each theme we consider challenges of human-technology-environment interactions and useful bridging concepts to consider these, such as 'ecosystem services'. Systematic critical discussions in each chapter of the role of science and the merits and limitations of scientific concepts and methods help to convey the uncertainties in our knowledge and set the foundations for critical interdisciplinarity and future-oriented dialectics.

The two first chapters in this part explore the transformation of agricultural systems to greater sustainability from two different perspectives. Chapter 9 by Nicolas Dendoncker and Emily Crouzat, geographers, characterises three past agricultural revolutions with attention to changes in land use and its consequences; subsequently the chapter maps out requisites for a fourth revolution towards a more sustainable agricultural system that relies on agroecology. The concept of ecosystem services plays a central role as a bridging concept to structure collaborative inquiry on stocks and flows in nature and to better understand diverse sets of values associated with these in diverse communities. Chapter 10 by Federico Davila and Robert Dyball introduces a conceptual tool from the field of human ecology, the cultural adaptation template (CAT), to explore in more detail the relations between the state of the environment, human well-being, human culture and human institutions, and unintentional as well as policy-based 'designed' feedbacks between them. This tool is then applied in support of a discourse analysis of two prevailing discourses in food politics: one focussing on technological innovation to solve food security issues, and one directing attention to self-reinforcing equity issues in the global food production system. These juxtaposed insights on the merits and limitations of problem framing in each of these discourses open a creative space to think about alternative futures and possible policy design afresh.

The three subsequent chapters engage with challenges in transformations of our energy system. Building on Samadi et al. (2016), three types of complementary measures are distinguished: those aiming at consistency by replacing fossil fuel-based energy sources with renewables, efficiency gains allowing us to do more with less, and sufficiency measures with the ultimate aim of reducing demand for energy-intensive products and services, such that efficiency-related gains are not merely reinvested into more energy demand-generating activities. In Chapter 11 Susanne Siebentritt, a physicist, introduces the readers to basic principles of physics, placing emphasis on the fact that energy is only ever transformed from one form into another, not actually consumed or used up. Some forms are more accessible and storable and versatile for human use than others. On this basis some key design requisites for future sustainable energy systems are characterised. Chapter 12 by Julia Affolderbach, Bérénice Preller, and Christian Schulz provides insights from research in the field of geography on transitions in the green building sector and drivers of change and reasons for lockins in unsustainable practices in four case studies distributed across three continents. Chapter 13 by Hondrila et al., which is actually written by a peer group based on a practice-embedded project during one academic year of the certificate in sustainability and social innovation, explores challenges to democratizing renewable energy in Luxembourg, with reference to recent related developments in Germany.

The last chapter in this section, Chapter 14 by Kim Chi Tran and Ariane König, then explores the role community-based monitoring and citizen and civic science 


\section{Ariane König}

might play in reconfiguring the problematic science-policy-practice interface for sustainable water governance.

\section{Part III: Tracking, steering, and judging transformation}

Part III discusses the role of measurement regimes and sets of indicators in defining and tracking progress. We are surrounded by quantitative indicators. They are one of the main channels whereby the citizen interacts on a day-to-day basis with science. How can the citizen make decisions in this jungle of indicators? Indicators are not simple facts about the world, but are the products of design, constructed from data, assumptions, and conventions. For the citizen, the question is not so much about the truth of some indicator, but about its quality. Moreover, measurement regimes act as devices for steering development across various levels of social organization and governance from diverse perspectives, including sociology and practice. The misuse and abuse of numbers in society and the neglect of representation of associated uncertainties is thematised, drawing on prior writings of Ravetz. Chapter 15 by Jerome Ravetz, Paula Hild, Julien Bollati, and Olivier Thunus identifies and critically discusses quality criteria for indicators in such measurement regimes. On this basis we deliberate on strengths and limitations of some statistical indicators, as well as other measures developed to motivate societal transition to sustainability - notably the Ecological Footprint. The assessment of the quality of an indicator, particularly one that is compounded from data relating to diverse fields of activity, is a demanding task from which value commitments cannot be kept separate. The NUSAP notational system, representing the range of attributes of scientific information from the most quantitative to the most qualitative, can be very useful in aiding the assessment of indicators. The Ecological Footprint, one of the most popular and influential sustainability indicators, performs a diversity of functions; the discussion of its merits and limitations is correspondingly complex.

Chapter 16 by Sebastian Manhart argues that in order to reflect and engage in complex transformative processes for sustainability, it is necessary to better understand how humankind approaches complexity on an individual and societal level, using numbers as well as other signs such as letters, language, and pictures. This chapter presents a conceptual framework to analyse how different categories of signs are used to represent complexity, using language, numbers, and pictures independently and in combinations. Each category of signs is associated with limiting rules on their assembly and interpretation for sense-making and communication. From this perspective, transformative learning requires a synthesis of diverse subjective and social constructions. The argument in this chapter is that most effective for this purpose are representations that draw and combine diverse logics of diverse sign categories, including numbers, language, and pictures. Different ways of representing complexity will result in drawing different productive boundaries around systems of interest. Reflection about merits and limitations of each sign category will make us more effective in using them in combination to better understand, communicate, and act upon complex circumstances.

Given the prevailing logics for governance in our liberal democracies that are rooted in neo-classical economics, the penultimate Chapter 17 by Jerome Ravetz asks what a reformed science of economics might contribute to sustainability. The use of numbers and language in the form of concepts and paradigms in the disciplined science of economics is critically discussed. 
Chapter 18 by Jerome Ravetz is a post script that presents the attributes of sustainability science conceived as transformative social learning process as a basic set of heuristics in more detail and relates why just this set of heuristics is significant in view of his analysis of the current crisis of legitimacy in science and expertise, in particular when drawn upon in technocratic forms of government.

Chapter 19 by Ariane König offers an outlook on the theory and practice of future transformative sustainability science. It briefly draws together insights across all chapters and concludes with more general guidance for designing and implementing research and learning initiatives for the practice of transformative sustainability science.

\section{Questions for comprehension and reflection}

1 Why are traditional approaches to knowledge production that have evolved over the past 200 years inadequate to address existential challenges of the twenty-first century?

2 What distinguishes descriptive and transformative sustainability science?

3 What can be learnt from the practice of transformative sustainability science?

\section{Note}

1 www.ucl.ac.uk/excites/home-columns/full-what-is-extreme-citizen-science/

\section{References}

Barth, M. (2015). Implementing sustainability in higher education: Learning in an age of transformation. London and New York: Routledge.

Burt, G. \& van der Heijden, K. (2008). Towards a framework to understand purpose in futures studies:The role of Vickers' appreciative system. Technological Forecasting and Social Change 75 (8): 1109-1127. doi:10.1016/j.techfore.2008.03.003

Castree, N. (2015). Geography and global change science: Relationships necessary, absent, and possible. Geographical Research 53 (1): 1-15. doi:10.1111/1745-5871.12100

Clark, W. C. (2007). Sustainability science: A room of its own. PNAS 104 (6): 1737-1738.

Clark, W. C. \& Dickson, N. M. (2003). Sustainability science:The emerging research program. PNAS USA 100 (4): 8059-8061. doi:10.1073/pnas.1231333100

Costanza, R., Kubiszewski, I., Giovannini, E., Lovins, H., McGlade, J., Pickett, K. E., . . . Wilkinson, R. (2014). Time to leave GDP behind. Nature 505: 283-285.

Crosby, A.W. (2015). Ecological imperialism: The biological expansion of Europe, 900-1900. Cambridge: Cambridge University Press.

Dewey, J. (1938). Education and experience. New York: Simon and Schuster.

Dietz,T., Ostrom, E. \& Stern, P. C. (2003). The struggle to govern the commons. Science 302 (5652): 1907-1912.

Dyball, R. \& Newell, B. (2015). Understanding human ecology: A systems approach to sustainability. Oxon: Routledge.

Fernandez-Gimenez, M., Ballard, H. L. \& Sturtevant, V. E. (2008). Adaptive management and social learning in collaborative and community-based monitoring: A study of five community-based forestry organizations in the Western USA. Ecology and Society 13: 4-19.

Funtowicz, S. \& Ravetz J.R. (1990). Uncertainty and quality in science for policy. Kluwer:Dordrecht. 


\section{Ariane König}

Funtowicz, S. O. \& Ravetz, J. R. (2015). 'Peer review and quality control', in Wright, J. D. (Ed.) International encyclopedia of the social \& behavioral sciences, 2nd edition. Oxford: Elsevier. pp. 690-694.

Funtowicz, S. O. \& Ravetz,J.R. (1993). Science for the post-normal age. Futures 25 (7): 739-755.

Grunwald, A. (2011). Energy futures: Diversity and the need for assessment. Futures 43 (8): $820-830$.

Grunwald, A. (2016). Nachhaltigkeit verstehen: Arbeiten an der bedeutung nachaltiger entwicklung. München: Oekom Verlag.

Hajer, M. A. (1995). The politics of environmental discourse: Ecological modernization and the policy discourse. Oxford: Oxford University Press.

Haklay, M. (2015). Citizen science and policy: A European perspective. Washington, DC: Woodrow Wilson Center for International Scholars.

Hargreaves, L. G. (2008). The whole-school approach to education for sustainable development: From pilot projects to systemic change. Policy and Practice: A Development Education Review 6: 69-74.

Hulme, M. (2009). Why we disagree about climate change: Understanding controversy, inaction and opportunity. Cambridge: Cambridge University Press.

Ison, R., Roling, N. \& Watson, D. (2007). Challenges to science and society in the sustainable management and use of water: Investigating the role of social learning. Environmental Science and Policy 10 (6): 499-511. doi:10.1016/j.envsci.2007.02.008

Jasanoff, S. (2015). 'Future imperfect: science, technology and the imaginations of modernity', in Jasanoff, S \& Kim S.-H. (Eds.), Dreamscapes of modernity: Sociotechnical imaginaries and the fabrication of power. Chicago: University of Chicago Press. pp. 1-33.

Jasanoff, S. (2003). Technologies of humility: Citizen participation in governing science. Minerva 41 (3): 223-244. doi:10.1023/A:1025557512320

Jerneck, A., Olsson, L., Ness, B., Anderberg, S., Baier, M., Clark, E., . . Persson, J. (2011). Structuring sustainability science. Sustainability Science 6 (1):69-82. doi:10.1007/s11625010-0117-x

Kates, R. W., Clark, W. C., Corell, R., Hall, J. M., Jaeger, C. C., Lowe, I., . . Svedin, U. (2001). Sustainability science. Science 292 (5517): 641-642. doi:10.1126/science.1059386

Keen, M., Brown,V. A. \& Dyball, R. (Eds.) (2005). Social learning in environmental management: Towards a sustainable future. London and New York: Earthscan.

König, A. (Ed.) (2013). Regenerative sustainable development of universities and cities: The role of living laboratories. Cheltenham, UK: Edward Elgar.

König, A. (2015a). Towards systemic change: On the co-creation and evaluation of a study programme in transformative sustainability science with stakeholders in Luxembourg. Current Opinion in Environmental Sustainability 16: 89-98.

König, A. (2015b). Changing requisites to universities in the 21st century: Organizing for transformative sustainability science for systemic change. Current Opinion in Environmental Sustainability 16: 105-111.

Kuhn, T. S. (1962). The structure of scientific revolutions. Chicago: University of Chicago Press.

Lakoff, G. \& Johnson, M. (1980). Metaphors we live by. Chicago: University of Chicago Press.

Lotz-Sisitka, H., Wals, A.E.J., Kronlid, D. \& McGarry, D. (2015). Transformative, transgressive social learning: Rethinking higher education pedagogy in times of systemic global dysfunction. Current Opinion in Environmental Sustainability 16: 73-80. doi:10.1016/j. cosust.2015.07.018

Maggs, D. \& Robinson, J. (2016). Recalibrating the Anthropocene: Sustainability in an imaginary world. Environmental Philosophy 13 (2): 175-194. doi:10.5840/envirophil201611740 
Matson, P., Clark, W.C. \& Andersson, K. (2016). Pursuing sustainability: A guide to the science and practice. Princeton, NJ: Princeton University Press.

Medema,W.,Wals, A. \& Adamowski, J. (2014). Multi-loop social learning for sustainable land and water governance:Towards a research agenda on the potential of virtual learning platforms. NJAS - Wageningen Journal of Life Sciences 69: 23-38.

Merton, R. K (1973). The sociology of science: Theoretical and empirical investigations. Edited and with and introduction by Storer, N.W. Chicago: University of Chicago Press.

Miller, T. R., Wiek, A., Sarewitz, D., Robinson, J., Olsson, L., Kriebel, D. \& Loorbach, D. (2013). The future of sustainability science: A solutions-oriented research agenda. Sustainability Science 9 (2): 239-246. doi:10.1007/s11625-013-0224-6

Millgram, E. (2015). 'The great endarkenment', in Millgram, E. The great endarkenment: Philosophy for an age of hyperspecialization. Oxford: Oxford University Press. Chapter 2. pp. 21-53.

Newell, B. (2012). Simple models, powerful ideas: Towards effective integrative practice. Global Environmental Change 22 (3): 776-783. doi:10.1016/j.gloenvcha.2012.03.006

Newell, B. \& Doll, C. (2015). Systems thinking and the cobra effect. Tokyo: United Nations University.

Newell, B. \& Proust, K. (2012). Introduction to collaborative conceptual modelling. Working paper, ANU Open Access Research. Retrieved from https://digitalcollections.anu.edu.au/ handle/1885/9386

Newell, B. \& Proust, K. (2017). 'Escaping the complexity dilemma', in König, A. (Ed.) Sustainability science: Key issues in connecting learning, research, and practice. Abingdon: Routledge. Chapter 5.

Newell, B. \& Siri, J. (2016). A role for low-order system dynamics models in urban health policy making. Environmental International 95: 93-97.

O'Brien, K. (2012). Global environmental change II: From adaptation to deliberate transformation. Progress in Human Geography 36 (5): 667-676. doi:10.1177/0309132511425767

O'Brien, K. (2015). Political agency: The key to tackling climate change. Science 350 (6265): 1170-1171. doi:10.1126/science.aad0267

Ostrom, E. (2009). A general framework for analyzing sustainability of social-ecological systems. Science 325: 419-422. doi:10.1126/science.1172133

Ostrom, E. (2010). Beyond markets and states: Polycentric governance of complex economic systems. Transnational Corporations Review 100 (3): 641-672.

Oxford English Dictionary. (2014). OED Online: The definitive record of the English language. Oxford: Oxford University Press. www.oed.com

Parodi, O. (2008). Technik am fluss. München: Oekom Verlag.

Peters, S. \& Wals, A.E.J. (2013). 'Learning and knowing in pursuit of sustainability: Concepts and tools for transdisciplinary environmental research', in Krasny, M. E. \& Dillon, J. (Eds.) Trading zones in environmental education: Creating transdisciplinary dialogue. New York: Peter Lang. pp. 79-104.

Ravetz, J.R. (2006). Post-Normal Science and the complexity of transitions towards sustainability. Ecological Complexity 3:275-284.

Raskin, P. (2016). Journey to Earthland:The great transition to planetary civilization. Boston:Tellus Institute.

Reddy, M. J. (1993). 'The conduit metaphor: A case of frame conflict in our language about language', in Ortony, A. (Ed.) Metaphor and thought. Cambridge: Cambridge University Press. pp. 164-201.

Robinson, J., Berkhout,T., Cayuela, A. \& Campbell,A. (2013). 'Next generation sustainability at the University of British Columbia: The University as societal test-bed', in König, A. 
(Ed.) Regenerative sustainable development of universities and cities: The role of living laboratories. Cheltenham, UK: Edward Elgar. pp. 27-48.

Robinson, J., Burch, S., Talwar, S., O’Shea, M. \& Walsh, M. (2011). Envisioning sustainability: Recent progress in the use of participatory backcasting approaches for sustainability research. Technological Forecasting and Social Change 78 (5): 756-768.

Rockstrom, J., Steffen, W., Noone, K., Persson, A., Chapin, F. S., Lambin, E. F., . . Foley, J. A. (2009). A safe operating space for humanity. Nature 461 (7263): 472-475. doi:10.1038/461472a

Rorty, R. (1999). Philosophy and social hope. London: Penguin Books.

Samadi, S., Gröne, M.-C., Schneidewind, Uwe, Luhmann H.-J.,Venjakob, J. \& Best, B. (2016). Sufficiency in energy scenario studies: Taking the potential benefits of lifestyle changes into account. Technological Forecasting \& Social Change - available online 3 October 2016. doi:10.1016/j.techfore.2016.09.013

Schneidewind, U. \& Singer-Brodowski, M. (2014). Transformative wissenschaft. Marburg: Metropolis Verlag.

Schneidewind, U., Singer-Brodowski, M., Augenstein, K. \& Stelzer, F. (2016). Pledge for a transformative science: A conceptual framework. Wuppertal Papers, No. 191. Retrieved from http://nbn-resolving.de/urn:nbn:de:bsz:wup4-opus-64142

Steffen, W., Richardon, K., Rockström, J., Cornell, S. E., Fetzer, I., Bennett, E. M., . . Sörlin, S. (2015). Planetary boundaries: Guiding human development on a changing planet. Science 347 (6223): 736-746. doi:10.1126/science. 1259855

Sterling, S. (2013). ‘The sustainable university: Challenge and response', in Sterling, S., Maxey, L. \& Luna, H. (Eds.) The sustainable university: Progress and prospects. Abingdon: Routledge. pp. $17-50$.

Stevens, M., Vitos, M., Altenbuchner, J., Conquest, G., Lewis, J. \& Haklay, M. (2014). Taking participatory citizen science to extremes. IEEE Pervasive Computing 13 (2): 20-29. doi:10.1109/MPRV.2014.37. Retrieved from http://ieeexplore.ieee.org/stamp/stamp.jsp $? \mathrm{tp}=$ \&arnumber $=6818498$ \&isnumber $=6818495$

Swart, R. J., Raskin, P. \& Robinson, J. (2004). The problem of the future: Sustainability science and scenario analysis. Global Environmental Change 14: 137-146. doi:10.1016/j. gloenvcha.2003.10.002

van der Sluis, J. (2005). Uncertainty as a monster in the science-policy interface: Four coping strategies. Water Science \& Technology 52 (6): 87-92.

Vickers, G. (1984). Judgement: Chapter 16 in the open systems group: The Vickers Papers. London: Harper \& Row. pp. 230-245.

Wals, A. E. J., Brody, M., Dillon, J. \& Stevenson, R. B. (2014). Convergence between science and environmental education. Science 344 (6184): 583-584. doi:10.1126/science.1250515

Wegerif, R. (2007). Dialogic education and technology: Expanding the space of learning. New York: Springer.

Wegerif, R., Li, L. \& Kaufman, J. C. (Eds.) (2015). The Routledge international handbook of research on teaching thinking. New York and London: Routledge.

Wiek, A. \& Lang, D. J. (2015). 'Transformational sustainability research methodology', in Heinrichs, H., Martens, P. \& Michelsen, G. (Eds.) Sustainability science - An introduction. New York: Springer. pp. 1-12.

Wiek, A.,Withycombe, L. \& Redman, C. L. (2011). Key competencies in sustainability:A reference framework for academic program development. Sustainability Science 6: 203-218. doi:10.1007/s11625-011-0132-6 